\title{
Policy Framework for Mobile Telecommunication Access Infrastructure
}

\section{E R D Mohan Silva and A T L K Samarasinghe}

Abstract: This study focuses on the issues of policy and procedures related to Cellular Towers and Antenna structures and their construction in Sri Lanka. In the Telecommunication Act of Sri Lanka, there is neither adequate provision nor concrete policy for tower and antenna structure construction. This has caused all stakeholders to suffer and face numerous problems in the process of telecommunication infrastructure construction.

The purpose of this research is to provide procedural guidelines and recommendations (Based on research analysis) for respective authorities to function smoothly. The broader objectives of the research are: to improve tower sitting consultation process and identify the most appropriate time frames for the processes of approving and resolving specific tower placements, to develop the plan to promote tower sharing in Sri Lanka, to encourage the operators to build suitable cellular tower installations ensuring public safety (Aesthetic, Lightening, RF issues, etc.) and to Determining the most useful and helpful information and the best means of providing it to concerned members of the public.

The development of this dissertation was mainly based on the information gathered through various groups such as General Public, Operators (Service providers), Telecommunications Regulatory Commission including other Government Authorities and other international best practices adopted by various regulatory authorities. A qualitative method known as content analysis was used to analyze the text provided in response to the open-ended questions. The empirical research comprised three strands: an online public consultation through web site and e-mails, a questionnaire survey for operators and regulator including other stakeholders, who were involved in tower approval process.

Following noteworthy findings were observed from the analysis:

a) The industry lacks an integrated policy for tower and antenna structure building process.

b) Tower approval process consumes extraordinary time due to too many stakeholder involvement (It delays the operator network rollouts) and needs improvement.

The lack of information to general public as observed today leads to enormous protests to installations owing to their concerns about common safety, aesthetic beauty and environmental impact

\section{Introduction}

Since late 1970s, there has been an increasing growth in telecommunication technology, particularly in the wireless sector. This growth is a result of accelerating demand for better communications and enhanced access across Sri Lanka. Due to subsequent rapid growth in the mobile telecommunication sector, the numbers of cellular tower installations have increased rapidly.

This study focuses on Cellular Tower and Antenna related issues in Sri Lanka. There is no concrete policy for antenna tower installations under Telecommunication Act. There are inclusions in the environmental authority ordinance on the tower and antenna structures viewed from the environmental point of view.

Nevertheless those policies do not provide adequately to control the existing issues in the country. However it is mandatory that Telecommunication Infrastructure related policies are comprehensively addressed in the Telecommunication Act.
ER D Mohan Silva, BSc. Eng., University of Morntuwa

Eng. A TLK Samarasinghe, BSc. Eng.(Moratuwa), M.B.A.(SriJ), C.Eng, MIE(Sri Lanka), Hend of Department, Dept. of Electronic and Telecommunication, Univirsity of Moratuwn 
Therefore the existing Telecommunication policy needs to be revised and reorganized to protect all stakeholders and environment from the rapid expansion of Mobile Communication Infrastructure such as cellular towers and antennas.

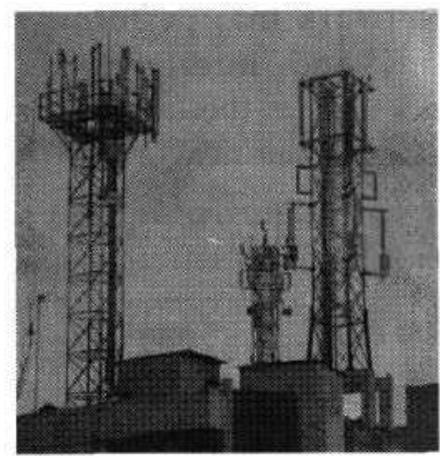

figure 1: Iower installations in close proximity

It is also suggested that this telecommunication policy is reviewed every year and that laws should be enforced to safeguard these policies. According to figure 1 there are lot of installations that do not meet the standards and the basics of the tower installation requirements. According to the environmental authority policy there cannot be tower installations in close proximity to one another (more than 500meters apart) but there are lot of installations implemented within this range due to lack of rules and regulations in the country. The other area that is neglected is the aesthetic impact or appearance of antenna masts. It is suggested that we should be more receptive to aesthetics if we are to promote tourism in Sri Lanka. To avoid this kind of situations Sri Lanka needs to establish effective and realistic policies under Telecommunication Act.

\subsection{Research Problem}

\subsubsection{Operator perspective}

There are several parties involved in the tower approval process such as Central Environmental Authority, Department of Civil Aviation, Ministry of Defence, Urban Development Authority and Telecommunications Regulatory Commission on a compulsory basis and Ministry of Forestry \& Environment, Ministry of Health and Ministry of Information \& Media on as occasional basis. The Local Government body that has power on this approval is the Pradesheeya Sabha. Due to this lengthy approval procedure it will take at least six months to get the final approval for the construction.

\subsubsection{People perspective}

\section{a) Environmental \& land use issues}

General concerns of the communities are that towers and antennas are beginning to invade the landscape. Community finds that the rapid growth in tower installations are damaging the natural and historic heritage of an environment due to the lack of land-use. The physical and visual degradation of the landscape that has outraged citizens and have triggered them to fight back to prevent the haphazard placement of towers and antennas in their communities. People fear that the towers and antennas will adversely affect property values and the quality of life in their communities. Unplanned installation of telecommunication towers destroys national historical heritage value.

Several towers built in one place can harm the cultural and historical value and the scenic beauty of the country.

\section{b) Lightening issues}

The general view of the people is that the threats of lightening strikes to dwelling houses have increased in tower sitting areas. The ignorance of general public gives rise to different presumptions like people sitting in their homes get slight shocks though not amounting to fatal damages but creating lethal scare.

\section{c) Other health and RF issues}

The safety against cellular mobile phone towers is a subject of extensive scientific debate. There is a growing body of scientific evidence that the electromagnetic radiation they emit, even if they are of lower strength, is dangerous to human health. The general view of the people is that if one were to live in a city with a transmitter in close proximity, chances of getting exposed to radio frequency or radiation is very high. Meanwhile, some studies have showed that there is evidence about the radiation from towers causing cancer or other health hazards. 


\subsubsection{Regulatory perspective}

\section{a) Regulatory issues}

There was some question about the output power of Radio Frequency (RF) signal within the limits of standards recognized by TRCSL from a health point of view.

\section{b) Standard of towers \& Breaking of rules}

TRCSL needs to have adequate law and regulations, and policies to take firm actions against non-standard tower installations. It has been reported that there is a lot of illegal tower installations but that is not possble to take proper action due to inadequacy of law.

\section{c) Information database}

The information database which provides information about cellular towers and they impacts and issues, is an important and a mandatory tool for the management of telecommunication sector. This is more emphatically needed for a country like Sri Lanka because there is a lot of public opposition due to unawareness. TRCSL needs to take action to introduce online web access to these information databases.

\subsection{Major Objectives of this study}

1. To improve tower sitting consultation process and identify the most appropriate time frames for the processes of approving and resolving specific tower placements.

2. To develop a plan to promote tower sharing in Sri Lanka. The carriers and other telecommunication tower owners are encouraged to work co-operatively in reaching agreements which allow for the sharing of tower structures so as to minimize the total number of towers in the city.

3. To encourage the operators to build suitable cellular tower installations ensuring public safety and rearranging the existing cellular tower infrastructure and addressing lower related issues (Aesthetic, Lightening, RF issues, etc.)

4. To determine the most useful and helpful information and the best means of providing it to concerned members of the public.

\subsection{Scope \& Limitation}

Mobile Telecommunication Infrastructure can be divided into two segments:

1. A Radio Access Network that performs airinterface related functions

2. Core Network that performs switching functions and interfaces to external networks such as the Internet or a publicswitched telephone network (PSTN)

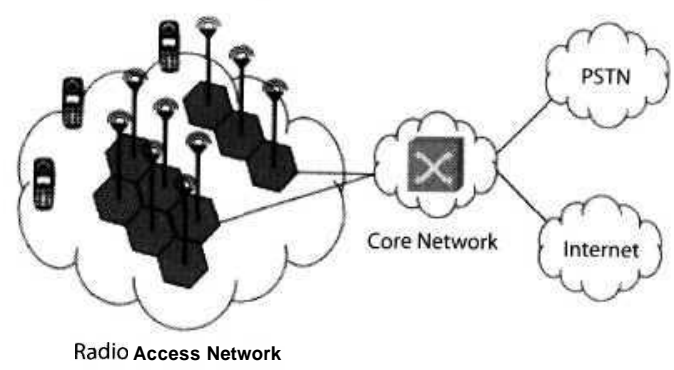

Figure 2: Mobile Communication system Infrastructure

This study mainly focuses on Radio Access Network (Figure 2) related issues in Sri Lanka such as:

a) Operator issues (approval delays)

b) Involvements from various departments

c) People issues (safety)

d) Environmental issues

e) RF levels - health issues

f) Number of towers (Sharing issues)

This study covers a part of general public in Sri Lanka, who are living and not living near to the tower installations. This policy directives will not cover the law side of the policy and will need to be considered by anyone preparing this policy document. Some of the operators are reluctant to provide the tower related information due to tough competition within telecomm industry. A general public questionnaire answered by people who are having internet access and $20 \%$ of the participants were interviewed.

\subsection{Significance}

The significance of this study is to provide procedural guidelines and recommendations (Based on research analysis) for respective authorities to function smoothly in the following areas. 
a) To solve complexity in tower approval procedures

b) To promote tower sharing issues

c) Environmental issues

d) Lightening issues

e) Other health and land issues

f) RF issues

g) Violation of rules

h) Critical tower related Information to public

Finally, it is expected that the analysis will demonstrate why the regions need proactive planning and importance of comprehensive regulations and ordinances. Due to the increasing number of towers in the country, government needs a special tower policy to control the impact on the living standards and the environment. Most of the developed countries are having a separate tower policy to protect the interests of the citizens and the environment from illegal tower installations. These suggestions will be very helpful for the government in preparing its future policy for tower installations and government can expand this to other related areas like broadcasting, transmission (Micro wave) antenna towers. etc..

\section{Literature Review}

\subsection{Land-Use Issues and Approval Issues}

On March, 2003, the Minister of Industry in Canada established a new National Antenna Tower Policy by consulting citizens, communities and relevant authorities regarding improvements to the policy and sitting procedures for antenna tower placement. (Townsend, 2004)

\subsection{Infrastructure(Tower) Sharing}

The Ministry of Telecommunications India has been encouraging both GSM and CDMA operators to share mobile towers in India. This will further reduce infrastructure cost and make the sharing procedures easy. (Business Line News, 2007).

Info-communication Development Authority of Singapore (IDA) prepared the industry consultation paper on the $3 \mathrm{G}$ infrastructures sharing in Singapore. There are four (4) main approaches to sharing of the $3 \mathrm{G}$ network infrastructure: Site Sharing; Radio Network Sharing; Geographical Network Sharing; Total Network Sharing. (The proposed policy approach to $3 \mathrm{G}$ infrastructure sharing in Singapore, 2002). This is an excellent example and model to use when preparing the telecomm Infrastructure policies for Sri Lanka.

Also one of the policy papers for ICT development in rural areas of Sri Lanka has highlighted that operators in Sri Lanka are reluctant to rollout to rural areas due to doubts on return on investments. Therefore it is useful to consider sharing of the infrastructure in rural areas. (Fernando, 2005).

\subsection{Health Concerns of Cellular Transmitting Sites}

The safety of cell phone towers is the subject of extensive scientific debate. There is a growing body of scientific evidence that the electromagnetic radiation they emit, even at low levels, is dangerous to human health. (Karen J. Rogers, 2002)

There is a separate web site owned by Malaysian Communications and Multimedia Commission to provide information to public regarding RF radiation. In that web site $\mathrm{Dr}$. $\mathrm{Ng}$ has published a special document related to "Radiation, Mobile Phones, Base Stations and Your Health". This type of information is very useful for public to get an idea about the tower and antenna related impacts. (Kwan-Hoong, 2005)

In the United States the Federal Communications Commission (FCC) authorizes or licenses most RF telecommunications services, facilities, and devices used by the public, industry and state and local governmental organizations. Because of its regulatory responsibilities in this area the FCC often receives inquiries concerning whether there are potential safety hazards due to human exposure to RF energy emitted by FCC-regulated transmitters. (IEEE study, 2000)

The International Conference on Cell-tower Sitting - Linking Science \& Public Health, held on June, 2000 in Salzburg, Austria, to discuss and study the protection of public health from highfrequency electromagnetic fields in the different countries. (International Conference on Cell Tower Sitting Report, 2000) 
Research study done recently by Moratuwa University students for their final year projects regarding the "Public Exposure to RF and Microwave Radiation in Sri Lanka" was sponsored by TRCSL. This study included the measuring of exposure levels and calculating absorption levels of RF and microwave emissions ranging from $88 \mathrm{MHz}$ to $2.5 \mathrm{GHz}$ throughout Sri Lanka. Also this study highlighted the importance of carrying out SAR evaluations and RF exposure levels periodically to maintain them at acceptable levels for public safety. (Devanarayana, Gunawardena, Perera, Anjana, 2007)

\subsection{Tower Installation Impacts}

"The mayor of Pune city, Dipti Chaudhari, has directed the Pune Municipal Corporation (PMC) to pull down within fifteen days 103 illegal telecom towers erected on the terraces of many buildings in the city." (India Telecom weekly news letter, 2004). This issue happened in Pune, India and as a very good example for execution of the country's law and policies.

In Sweden Ericsson has redefined the telecommunications landscape with its cuttingedge Tower Tube solution. The breakthrough design employs innovative architecture and construction techniques that improve energy efficiency and reduce operator costs, while offering an aesthetically pleasing design. (Ericsson tower tube, 2007)

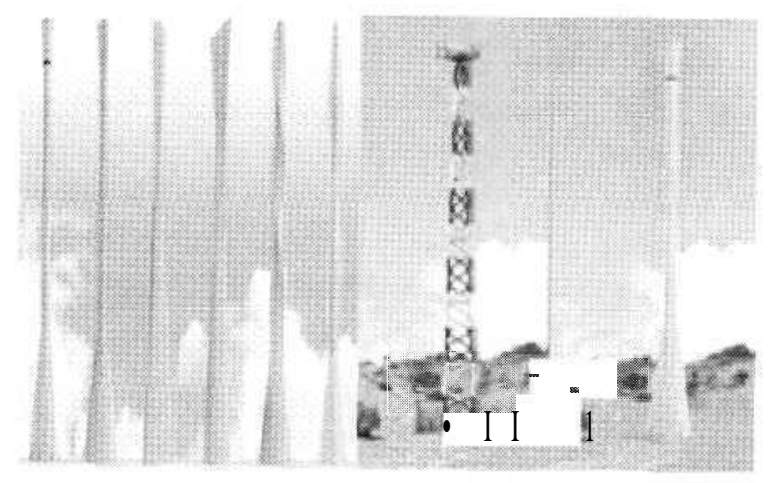

Source:http://www.ericsson.com/campaign/ towertube/

Figure 3: Tower tube replaces conventional telecommunication sites

\section{Methodology of study}

\subsection{Introduction}

A general methodology, which is called Inductive method, was used in this research to identify the issues related to tower installations. The development of this dissertation was mainly based on the information gathered through various groups such as General Public, Operator (Service provider), Regulator including other Government Authorities and other international best practices adopted by various regulatory authorities.

A qualitative method known as content analysis was used to analyze the text provided in response to the open-ended questions (specifically the operator and Regulator questionnaire). The purpose of this analysis was twofold. First, content analysis was necessary to systematically and objectively derive categories of responses that represented homogeneous thoughts or opinions. The second purpose of content analysis was to identify responses particularly germane to this investigation and deemed worthy of presentation in this report.

The form of content analysis performed is known as open coding or context-sensitive scheme coding. This form of analysis involves the researcher in naming categories through a detailed examination of the data. This involved an iterative interpretation process of first reading responses, then re-reading to establish meaningful categories, and finally re-reading select responses to refine the number and meaning of categories in a manner deemed most representative of the respondents' text.

\subsection{Data Collection}

Over the course of this period numerous methods of data collection were utilized in order to optimize opportunities for consultation with, and input from, all relevant and interested constituencies. The methods of data collection included following an interactive methods. An online public consultation through web site and emails. Survey questionnaire for Operator, Regulator and other government authorities. Inperson interviews with selected representatives of community associations, governmental departments, and the communications industry. Study the international Case Studies \& Reports 
to contrast how antenna supporting structures are being regulated in other countries.

\subsection{Sample Distribution:}

The total population of the study included individual citizens, TRCSL Management, government institutions participating in tower approval process and Operators.

Questionnaire distribution and the responses are shown below in Table 4.

\begin{tabular}{|l|c|c|}
\hline & Distributed & Respondents \\
\hline Operator & 7 & 6 \\
Public & 250 & 104 \\
Regulator & 2 & 2 \\
Local Authority & 2 & 2 \\
\hline
\end{tabular}

Table 1: Sample Distribution

\section{Analysis and Discussion of Results}

\subsection{Introduction}

This chapter reports the study findings based on the data and information gathered during the research study. This analysis based on operator, general public and regulator including other stakeholders' questionnaires. Operator's feedback is very important as they are the principle users of the law in the telecommunication industry. There are seven major telecommunication operators in Sri Lanka and only six operators answered to the questionnaire and one operator refused to answer due to present competition in telecom industry. Due to that it was not possible to get an exact count of tower installations in Sri Lanka. Following tower information is very important to the telecommunication industry.

Total number of cellular towers in Sri Lanka = 7700 (Approximately)

Total number of cellular towers forecasted for next five years $=7500$ (Approximately)

Total number of towers shared $=850$ (Approximately)-11\%

\subsection{Detailed Analysis}

The following sections will cover the detailed analysis of the data gathered during the literature and questionnaire survey. Below is a sample of comments posted in the discussion form, categorized generally under the four (4) objectives.

\subsubsection{Demographic characteristics}

The study includes operators, general public and the regulators including other stakeholders involved in tower approval process. Participants from operators are of managerial background with an average of 15 years experience in TelecomIndustry. Both participants from TRCSL are from managerial background and having average of 8 years in Tower approval process and 22 years of experience in Telecom Industry. One local authority officer and one provincial council member participated in the interview. The general public survey includes both male and female members and the composition of respondents is with a majority of males amounting to $81.7 \%$ out of the total. Almost all the participants were having mobile phones $(97.1 \%)$ and living in central urban area $(91.3 \%)$. $62.5 \%$ citizens were closed to the towers and the balance $37.5 \%$ were reported to live far away from the towers. Due to these reasons, the answers were not biased to one set of respondents. In order to facilitate analysis of the questionnaire results, all respondents were asked to "select the group that best represents you" from a list of five. Most of the participants were from public and telecommunication industry (43.3\% each). The mean age of the respondents was 36.02 years and having a range of 50 years. $38.5 \%$ and $30.8 \%$ participants are from 20-30 years and 31-40 years age groups respectively.

\subsubsection{Tower Consultation and Approval Process}

\section{Objective 1:}

Participants from Operators and the Regulator mentioned that present tower approval time frame is too long in contrast to the rapid growth and demand in the Telecommunication sector. In today's environment it takes around three to six months on average for tower approval. According to above answers all the operators and regulators would like to get tower approval 
finalized within two months. To achieve that government (TRCSL) needs to take the lead and get involved in tower approval process. All the participants from operators, regulator and other stakeholders believed that TRCSL needs to handle this process because local authorities are more politicized in doing this activity today. According to operator survey local authority officers are not able to handle these public complaints due to lack of technical knowledge.

According to the general public survey, $88 \%$ of the participants mentioned that public was not fully aware about the tower installations and that they like to get involved in public consultation process. Due to that government needs to set time lines for public consultation and notification processes. All participants agreed that one to two weeks are adequate enough to finalize the public consultation process. Most of the public protests were due to lack of knowledge hence public awareness programs need to be conducted regularly to improve the situation. According to general public survey $94 \%$ of the participants agreed that public awareness is a major part in this tower approval process.

A majority of participants expressed a desire to see a standardized consultation process across the country. The gravity of the problem lies with the inconsistency of policy on construction approval from one town to another or from one province to the other. Operators complained that sometimes provincial council members are demanding for donations or charity contributions to projects in the area to get site approvals processed. Due to that all participants would like TRCSL to lead this through-out the process. Some have suggested that from start to finish, the consultation process should take no longer than two weeks and the process and guidelines should be standardized across the country.

According to the above analysis Government (TRCSL) of Sri Lanka needs to prepare a proper policy document under Telecommunications Act. Public notification also very important in consultation process. However, presently there is no proper procedure or guidelines to notify the public and government needs to setup the guidelines and procedures to solve these tower related issues. According to this research most of the participants mentioned that media, newspaper, leaflets, seminars and public meetings would be effective ways of notifying the public. One mentioned that direct mail to residents in close proximity to tower should be the proper way of notifying the public.

Other stakeholders' involvement is very important in this approval process and government needs to pay much attention in reducing this approval timeframe. Presently approval is obtained from following institutions such as Central Environmental Authority, Department of Civil Aviation, Ministry of Defence, Ministry of Forestry \& Environment, Telecommunications Regulatory Commission and Municipality or Urban Council (Local Authority). All the participants mentioned that they prefer to have a single meeting with representatives of all the stakeholders in a set time frame and a majority preferred the Government (TRCSL) to coordinate all the stakeholders in handling this approval process. One of the operators mentioned that there should be a competent technical officer in every authority who can understand the issues regarding the operation of a telecommunication tower. This serves as a valid argument and in this way it is possible to avoid delays due to lack of knowledge.

\subsubsection{Tower Sharing}

\section{Objective 2:}

Tower sharing and co-location for commercial towers is seen as desirable by most of the groups who participated in this survey. A few would argue that towers are not an eye-sore, but they are a necessary evil for delivering wireless services. There are technical arguments for certain mismatches of technologies on a common tower, but for many scenarios mixed technologies and spectrum bands can coexist on a common tower. Sharing of towers will provide an economic benefit to service providers and reduce the negative aesthetic impact due to accumulation of towers.

According to the operator survey they have expressed the view that they would like to promote the tower sharing in Sri Lanka and at the same time they like Government (TRCSL) to take the lead in this process. Operators suggested to form a committee including operators and TRCSL. During the Regulator 
questionnaire survey the representatives agreed that there are no rules and regulations for tower sharing at the moment and that the Government's (TRCSL) responsibility is to prepare proper guidelines to promote the tower sharing throughout Sri Lanka.

According to the General Public questionnaire survey $86.5 \%$ of the participants agreed that Tower sharing should be mandatory for Sri Lanka, in order to reduce the number of tower installations due to rapid expansion in mobile industry. The General public mentioned that government should control tower sharing by introducing new tower policies. These public interest concerns provide further justification for policies that encourage tower sharing.

The successful implementation of antenna sharing policies does have a direct tie to local land-use consultations. If land-use authorities and citizens are sufficiently aware of Industry Sri Lanka policy requirements and expectations for site or tower sharing they can play a challenge function during consultations with the proponents to encourage more tower sharing. Also, well informed municipalities will be better prepared to work with antenna proponents to identify land or areas where multiple antenna sittings can be accommodated. In general public survey $59.6 \%$ (Table 22) of participants highlighted that there are no proper rules and regulations to take action against illegal tower installations (Including Roof-top towers). Also $35.6 \%$ participants were not aware about the situation. Due to that government needs to pay attention to educate the general public regarding these issues.

\subsubsection{Antenna Tower issues}

\section{Objective 3:}

Respondents were next asked a series of questions designed to gather further information on the specific issues that are sometimes raised in response to the sitting of new antenna towers. All operators and regulatory participants expressed that issues such as Aesthetics, Property value, Health concerns (RF exposure) and Lightening impacts are very important to the customers. Out of these issues "Health risks associated with radio frequency (RF) exposure" is the greatest concern. All the participants from operators and regulator suggested that this type of mentality can be removed only through awareness programs. All suggested that government needs to educate general public via meetings, open forums, internetetc.

During the general public survey $43.2 \%$ (Table 13) participants had concerns about the property value however $44.2 \%$ participants were not having any idea about property value. That means more than $50 \%$ of the participants did not agree with property value statement. Regarding the lightening issue public expressed same kind of reaction and $35.6 \%$ participants were undecided and less than 50\% not interested about the lightening issues. However $48.1 \%$ of the participants were concerned about the lightening issues. There are lots of complaints received by TRCSL related to lightening incidents and it was found that most of them were due to imperfect earthing of the towers. This is very critical for the public hence government (TRCSL) needs to have proper guide lines and resources to monitor tower grounding as a regular process.

Further according to the survey, respondents agreed that $56.6 \%$ of the participants are tormented about the health risks and $25 \%$ of the respondents were not aware about the situation. Also $70.2 \%$ of the participants mentioned that they are knowledgeable about the health risks associated with RF exposure. Respondents who are living close to towers were concerned about health risks due to RF exposure. During the literature survey it was found that there was a large number of research studies conducted to find the effects due to RF exposure. Children are at the greatest risk, due to their thinner skulls, and rapid rates of growth. Also at greater risk are the elderly, the frail and pregnant women. (Karen J. Rogers 2002).

Recently university students have done a research study to measure the RF exposure levels by the help of TRCSL, which was not done for a long period. These types of studies are very important to the country and TRCSL needs to sponsor or carryout these types of measurements every six months. Presently in Sri Lanka most of the operators are moving to $3 \mathrm{G}$ and Wimax technologies and it can increase the exposure levels in the environment due to high power transmitters. Therefore it is necessary to 
carryout continuous researches throughout the island to guarantee public safety. (Devanarayana, Gunawardena, Perera, Anjana, 2007)

Also people are anxious about environmental impacts due to antenna towers, such as historic value and aesthetics or appearance of antenna towers. During the public questionnaire survey $70.1 \%$ of the respondents were concerned about the environmental impacts. Still $27.9 \%$ of the participants were not knowledgeable about the environmental impacts. During the literature survey it was found that Sweden (Ericsson) has developed the Tower Tube concept of antenna towers. The breakthrough design employs innovative architecture and construction techniques that improve energy efficiency and reduce operator costs, while offering an aesthetically pleasing design. In Sweden operators and visitors are invited to experience the excitement of this landmark construction first hand through formal presentations and guided tours. Government (TRCSL) also can look into this kind of changes in antenna tower installations in Sri Lanka.

\subsubsection{Information about Antenna Towers and Impacts}

\section{Objective 4:}

During this survey respondents were asked to identify information needed by members of the public and to indicate how this information should be provided. Participants stated that there is no primary source of information used by members of the general public to learn about antenna towers and their potential impacts. $86.6 \%$ of the public survey participants agreed that information about tower installation impacts and other related issues are very important to general public and that the Government (TRCSL) needs to provide this information via media, advertising, television, website and news papers. Also there is no place to complain regarding the tower related issues, presently most of the people are complaining to provincial councils, Ministries or to the local authority, though such complaints should be lodged at a neutral authority which is TRCSL for an investigation. Basic information, as well as some technical information, was highlighted as important to educate the general public.

\section{Conclusions and Recommendations}

Several broad conclusions can be drawn from this analysis of the open and close ended questions on the operator, regulatory commission and general public questionnaires based on four research objectives.

Present tower approval time frame consumes extraordinary time and it is very difficult for operators to cater to the rapid growth and demand in telecommunication sector. Most of the operators are facing problems in rolling-out their $2 \mathrm{G}$ and $3 \mathrm{G}$ networks due to this extraordinary time frame. Government (TRCSL) needs to prepare proper rules and regulations to avoid all kinds of delays and corruption in this area.

There are no proper guide lines to follow and monitor the tower sharing in Sri Lanka and Government (TRCSL) needs to prepare these guide lines to control the number of towers in Sri Lanka.

According to the analysis general public is more concern about the issues such as aesthetic, property value, health concerns (RF exposure) and lightening strikes. Government needs to do more research on these areas which is directly affecting the general public. Existing rules and regulations needs to be updated and properly followed by the TRCSL according to research analysis.

Thisresearch provides following recommendations based on four research objectives.

\subsection{Policy requirement}

a) The legislative authority to regulate the sitting of radio communication antennas and their supporting structures should remain exclusively with the Government of Sri Lanka.

b) Strong policy guidelines preparation is mandatory for Cellular tower sector in Sri Lanka to overcome the issues related to cellular towerinstallations.

\subsection{Tower Location and Sitting}

c) Encourage monopoles - The use of monopoles is encouraged. Where a tower is being constructed to accommodate a single user, a monopole design is required. 
d) Use existing structures/buildings - When considering the sitting of telecommunication tower facilities, every effort should be made to locate new equipment on existing structures such as Hydro transmission towers, utility poles, public and municipal buildings, roof-tops etc.

e) Prefer non-residential locations - It is preferable that new telecommunication towers be sited in non-residential locations.

f) Discouraged locations - cellular towers on prominent natural and cultural features, environmentally sensitive areas or areas with historical significant buildings should be discouraged.

g) Justification - All applications for telecommunication towers should identify any other structure within a radius of 300 metres (Distance to be decided by the Government) of the proposed location and provide reasons why other existing structures within that radius are not acceptable for use.

\subsection{Public Consultation and Notification}

h) Notification and Consultation are required to be conducted by the Government (Local Authority) for all proposed antennas in any Residential or in an Industrial or Commercial District, as follows: (Distance and Height values to be decided by the Government)

i) For Antennas 15 meters (50ft) or less in height and located 100 metres from the nearest existing residential District;

ii) For antennas over 15 metres but less than 30 metres $(100 \mathrm{ft})$ in height and located 200 meters from the nearest existing residential District;

iii) For antennas over 30 metres but less than 45 metres $(150 \mathrm{ft})$ in height and located 400 metres from the nearest residential District;

iv) For antennas over 45 meters in height and located 600 metres from the nearest residential District. i) The applicant shall place an advertisement in the local newspaper and post an information sign not less than 1.5 metres by 1 metre on/or adjacent to the proposed site at a location clearly visible from the nearest road for a period of not less than 14 days.

j) The applicant shall advise all households within a radius of at least 250 meters of the tower location, in writing, of the proposal.

k) Written notice should be given at least ten (10) days before the Operator intends to engage in the low-impact activity.

\subsection{Dispute Resolution Process}

The Government will, based on the information provided, either:

1) Make a final decision on the issue(s) in question, and advise the parties of its decision; or

m) Suggest that the parties enter into an alternate dispute resolution process in order to come to a final decision. Should the parties be unable to reach a mutually agreeable solution, either party may request that the Department make a final decision.

n) The Commission has the power to intervene to resolve disputes at the request of either party and to impose facility sharing or collocation arrangements between operators after consultation with the parties.

\subsection{Tower Sharing}

o) Allow for sharing - All telecommunication companies are encouraged to work cooperatively in reaching agreements which allow for sharing of tower structures.

p) Applicants should first approach other Wireless Operators with respect to colocation on existing towers. If not feasible the Wireless Carrier is strongly encouraged to make arrangements with other Operators to allow co-location on the proposed new tower site. The other Operators need to respond in writing to this request within 14 days. If another Operator expresses a desire to colocate on the site, a meeting between the Operators is held within 14 days, to exchange further information and determine if co- 
utilization is feasible. (TRCSL needs to decide the responsibility and time frame)

q) That land-use authorities and members of the public should be fully informed about the site and tower sharing obligations or policy expectations set by Industry Sri Lanka for antenna proponents.

r) The possibility of negative aspects of sharing, such as technology interference, or amenity issues. Towers should be kept to a minimum and, whenever possible, tower sharing should be encouraged.

s) Tower sharing is encouraged, and applicants should explore this possibility before applying. If they do not consider tower sharing, they can be rejected by Government authorities for failing to do so.

t) Where a mobile phone station is added to an existing mast or site, the operator should confirm that the cumulative exposure will not exceed ICNIRP guidelines. Independent audit of emissions should be established to improve public confidence.

u) Government should pass rules and regulations to stop exclusive roof-top antenna installations.

\subsection{Aesthetics}

v) Towers and ancillary equipment shelters will be designed to fit their surroundings and to minimize their visual impact on surrounding properties.

w) All applicants for antenna structures which are visible from residential areas may be requested to employ innovative design measures to mitigate the visual impact of these structures.

\subsection{Health Risk and RF exposure}

x) Industry Sri Lanka should create a national risk communication strategy to respond to public questions and concerns about the health effects to humans from exposure to radiofrequency fields.

y) All the tower installations should meet International Commission on Non-Ionizing Radiation Protection (ICNIRP) guidelines. z) Land-use consultation materials prepared by Industry Sri Lanka should contain very basic information about electromagnetic interference (EMI), about obligations to resolve EMI problems and about Industry Sri Lanka's respective role.

aa) Government should monitor the RF exposure and the lightening impacts regularly. Government needs to allocate resources and necessary funds for these activities. (Every six monthspreferred)

bb) The public should have access to up-to-date information about standards and potential health risks. In addition, the industry should also keep abreast of scientific developments and share new information with the public.

\section{References}

A Consultation Document (2001) the proposed policy approach to $3 \mathrm{G}$ infrastructure sharing in Singapore, available at http://www.ida.gov.sg /doc/Policiesb\% 20and\%20Regulation/ Policies_and_Regulati on_Level2/ $3 \mathrm{G}_{-}$infra_sharing/3G_Infrastruct ure_Sharing.pdf. Visited, $22^{\text {nd }}$ June 2007

Business Line news, (2007) TRAI for sharing of active infrastructure. Available at http:// www.thehindubusinessline.com/2007/04/13/ stories $/ 2007041303910400 . h t m$. Visited, $26^{\text {th }}$ May 2007

Devanarayana T.I., Gunawardena P.S.K., Perera W.D.D., Anjana T.A.R, (2007) Public Exposure to RF and Microwave Radiation in Sri Lanka, BSc Final year project report, University of Moratuwa

Ericsson Tower Tube, Available at http:// www.ericsson.com/campaign/towertube/wh atisit.shtml. Visited, 5th Nov. 2007.

Fernando, K.A.D. (2005) ICT Development in Rural Areas of Sri Lanka, Policy Paper, MBA in MOT, University of Moratuwa.

IEEE study, (2000) "International Conference on Cell Tower Sitting" Linking Science \& Public Health Salzburg, Austria, June, 2000 available at http://www.land-sbg.gv.at/ cell tower. Visited, $27^{\text {th }}$ May 2007. 
Independent Expert Group on Mobile Phones, (2000) Mobile Phones and Health, available at http://www.iegmp.org.uk/report/text.htm. Visited, $22^{\text {nd }}$ October 2007.

India Weekly Telecom Newsletter, (July, 2004) "Telecom towers in Pune to be pulled down" available at http:// findarticles.com/p/articles/ mi_hb5 971/is_200407/ai_n24130054. Visited, 23rd June 2007.

International Conference on Cell Tower Sitting Report, (2000) Linking Science \& Public Health Salzburg, Austria, available at http://www.sal zburg.gv.at/salzburg_resolution_e.pdf. Visited, $23^{\text {rd June }} 2007$.

Kwan-Hoong, Dr. Ng (2005) "Radiation, Mobile phones, Base Station and Your Health" Frequently asked questions. Gains Print Sdn. Bhd. 1-22. Available at http:// www.rfrad.gov.my/english/ publicationsdetail.php?uid=e38ff72318806574d5cl

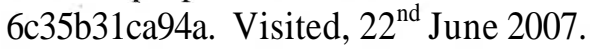

Rogers, Karen J. (2002) Health Effects from Cell Phone Tower Radiation. Available at http:// healtheffectsfromcell_phone_tower_r adiation.doc. Accessed on 24/06/2007

Townsend, David A. (2004) Report On: the National Antenna Tower Policy Review. Available at http://strategis.ic.gc.ca/epic/site/ smt-gst.nsf/v wapj/antennareport-e.pdf/ \$FILE/antennareport-e.pdf. Visited, $26^{\text {th }}$ May 2007. 